\title{
The social value of the arts for care home residents in England: A Social Return on Investment (SROI) analysis of the Imagine Arts programme
}

Alessandro Bosco ${ }^{1}$, Justine Schneider ${ }^{2}$

Affiliation: ${ }^{1}$ Division of Psychiatry and Applied Psychology, School of Medicine, University of Nottingham, Nottingham, United Kingdom; '2School of Sociology and Social Policy, University of Nottingham, Nottingham, United Kingdom;

Corresponding author: Alessandro Bosco, Room A10, Institute of Mental Health, Innovation Park, University of Nottingham, Triumph Road, Nottingham NG7 2TU, United Kingdom. Email: Alessandro.bosco@nottingham.ac.uk Phone: (+44) 7453512212. 


\section{Abstract}

Background: Direct involvement in creative activities can have benefits in terms of improved attention and positive engagement for older people. We used the Social Return on Investment approach (SROI) to explore the social and economic benefits of arts activities for older people living in residential homes in England.

Methods: We complied with the CHEERS checklist and followed the six stages of SROI as reported in the literature.

Results: We identified three main stakeholders: care home residents, care home personnel, and activity co-ordinators. For residents, the outcomes of interest were: community inclusion, mental and physical health, improved cognition and decreased social isolation. For care home personnel and activity co-ordinators the outcomes were: improved skills in caring for older people and increased confidence in using arts intervention. The analysis yielded an SROI of $£ 1.20$ for every $£ 1$ of expenditure.

Conclusions: Findings could inform policy decisions about investment in the arts and health or social care.

Words count: 150/150

Keywords: Social Return on Investment, stakeholders, care homes, older people, arts. 


\section{Introduction}

Charities and other Third Sector organisations in the UK have pioneered the pursuit of evidence concerning social value in community interventions [1,2]. The Public Services (Social Value) Act [3] also requires public authorities to have regard to economic, social and environmental well-being in connection with their commissioning contracts. This therefore applies to the procurement of residential care for older people by local authorities, including, by implication, the activities provided in such settings. In England there are over 30,000 homes registered with the Care Quality Commission to provide residential and nursing care [4]. Each typically offers accommodation for about 25 individuals. About $75 \%$ of residents are female, the average age is over 85 , and over $60 \%$ of residents are affected by dementia [4]. The activities available to occupy, divert and stimulate residents are therefore limited, due to the high levels of disability - physical as well as cognitive - and the relatively high cost of skilled personnel in a context of shrinking budgets [4]. A typical home might offer one kind of activity on most days from the following range: manicures, bingo, karaoke, armchair exercises, card making or a bus trip to a local venue [5].

There is growing interest in the benefits of arts participation for older people, including those who are cognitively impaired [6]. It has been suggested that involvement in creative activities can increase motivation, a sense of competence or purpose, and improve the quality of life of participants [7]. Benefits may be carried over to other areas of everyday life, and improve attention, appetite, communication and social engagement [7-9]. Promising positive effects have been evidenced across a range of activities including visual art [10,11], music or singing $[12,13]$ and storytelling [14]. Participatory arts have been found to lead to significant positive effects in the mental wellbeing, general health and social functioning of older people $[15,16]$. Positive outcomes have also been found for activity co-ordinators and care home personnel who provide such activities. These include greater job satisfaction, increased social opportunities, improved knowledge around the needs of people they care for, and professional skills development $[17,18]$. In relation to the outcomes for the artists, there is 
very limited reporting of their subjective experience [5]. One previous SROI analysis reported non-financial benefits from arts activities for care home providers, whose organisations gained publicity following the artistic programme (Craft Café) [19].

Social Return on Investment analysis (SROI) is a widely-used approach to evaluate the wider impact of investment in relation to public benefit $[20,21]$. With an emphasis on the engagement of stakeholders in the evaluation process, SROI can be seen to empower its participants and to promote positive relationships between different groups engaged in a common enterprise. It is akin to cost-benefit analysis, in that it assigns a monetary value to outcomes, both positive and negative, thus enabling different activities to be compared in monetary terms $[22,23]$. However, the SROI approach entails the inclusion and quantification of dis/benefits which are not amenable to direct measurement. For example, SROI might look at the impact of a development on: an organisation's reputation, the confidence of staff or the autonomy of frail older people. It therefore relies heavily on the transparency of the estimates used and on arguments to justify these - such as the exploration of counterfactuals. A body of practice standards has been built up to assure the quality of SROI analyses [24], but the method is still developing $[25,26]$. Therefore, its application needs to be carefully contextualised, and its results derived rigorously, using both argument and evidence.

A recent review of SROI studies found 40 , which varied in quality and covered a wide range of areas of public health (e.g. health promotion, mental health, sexual health and child health) [27]. None focussed on arts interventions in care home settings, so we undertook a further search to identify any relevant literature. Our search found only two reports: BrendonCare for older people [28], and the Craft Café study [19]. These had widely-different SROI ratios of 1.4 and 8.2 respectively. The All-Party Parliamentary Group (APPG) Inquiry Report published in July, 2017 [29], cites several SROI ratios in its evidence concerning social prescribing (APPG, $p$ 5), including our own preliminary findings (p135) but these have 
not been assured by peer review. There is a great need for more research to build an evidence base concerning the social benefits of the arts to society.

The Imagine Arts programme aimed to experiment with the delivery of high-quality arts interventions in care homes. It was set in an area of central England with an estimated population of 300,000 [30]. Seventeen residential care homes from the public, private and voluntary sectors were involved in the programme over three years (2014-17). To explore and understand the impact of arts activities on quality of life, mental wellbeing, and general health of the stakeholders involved, an SROI analysis of the Imagine study was performed by the authors as part of a wider evaluation $[5,17]$. The present paper reports that analysis; it describes the methodology and then presents an impact map of the Imagine Arts programme, estimates the SROI ratio, explores the factors which influence this result and reflects on the limitations of the approach in this context. Our research question is: What overall impact do professionally-led artistic programmes delivered in care homes have on the stakeholders involved?

\section{Research approach and methodology}

This study complies with the CHEERS (Consolidated health economic evaluation reporting standards) checklist for health economic evaluations [31]. This SROI analysis is grounded in the principle of transparency in reporting the results and is based on the six stages of SROI evaluation [32]:

1. Identification of the scope of the study.

2. Identification of the stakeholders.

3. Identification of the outcomes (what has changed as a result of the delivery of the activity).

4. Determination of the materiality of the outcome.

5. Application of a monetary value for the proxies.

6. Report of the impact and calculation of the SROI. 
Sensitivity analysis is further performed by altering the values of some of the assumptions used for the analysis of the SROI. The alterations may occur in proxies, outcomes, deadweight, attribution, displacement, and drop off [21], which are explained in the relevant sections below.

The delivery model was designed to ensure the co-participation of residents, artists and care home providers in the development of the Imagine programme (Figure 1). As the figure suggests, residents were at the core of the circle. They were systematically consulted through interviews and questionnaires about their preferred arts activities during the settingup period of about 6 months. With respect to the arts programmes delivered, all older people and their respective carers were individually asked to nominate their favourite activities, so that the arts components to be included in the arts programmes were based on their preferences. Music, singing/choirs, visual arts, dance, live performances broadcast within the home and visiting art galleries resulted the most preferred artistic components (Table 1). From these, a series of professionally-led arts programmes were developed and tailored to the needs of older people (e.g. the support of a carer, the use of strategies to enhance their understanding such as repetition of concepts). The programmes were:

- Armchair Art Gallery. This programme was inspired by MoMA (Meet Me project) [33] and aimed to guide residents to the artistic world of art galleries using IPads.

- Open Arts Forum. This programme comprised a series of visits to arts venues to view and discuss visual exhibitions.

- Mixed Reality Lab Residency. This programme aimed to explore digital technologies.

- Theatre. This artistic programme aimed to deliver co-produced work, developed by older people, their families and care staff.

- Live streaming. This aimed to enable care home residents to experience live classic piano recitals and events through the internet.

Artist residencies took place in participating care homes such as (e.g. outdoor and visual arts, creative writing, dance and singing). Some of the art work generated through these 
activities required more sessions to be completed (e.g. the creation of the giant bird for the local Carnival) others required only one session (e.g. story telling). Each session typically ran for 1 to 2 hours. There was no restriction in the number of people who could attend each session. However, the number of attendees ranged from 5 to 30 .

\section{Scope of the analysis}

This analysis is based on data collected between February 2014 and December 2015 (6 quarters), during which time the programme was fully established and running arts activities in care homes.

\section{$\underline{\text { Stakeholders }}$}

The four categories of stakeholder used by Banke-Thomas, Madaj, Charles and van den Broek [2] were operationalised as follows:

- Beneficiaries: Those who experience the outcomes of an intervention (care home residents, care home personnel, and participating activity co-ordinators to the study).

- Implementers: Suppliers and subcontractors (artists).

- Promoters: Those who provide support and a conducive environment for implementation of the intervention (care home providers).

- Funders: Those who directly finance the project (Baring Foundation, Arts Council England, Nottingham City Council).

\section{Theory of change}

A theory of change was developed according to the expected changes experienced by the stakeholders as a consequence of their involvement in the study (Figure 2). Inputs and outcomes were calculated separately for each of the first three groups of stakeholders above, who were judged potentially to derive benefit (or harm) from participation. Funders were only included for the input they invested for the delivery of the programme; they were not treated here as potential beneficiaries as no material outcomes were anticipated as a result of their involvement in the programme. The co-ordinating organisation, which 
implemented and directed the programme and commissioned the SROI evaluation, was excluded from the scope of analysis.

\section{$\underline{\text { Outcomes }}$}

Many of the outcomes of interest were evident from the rationale for funding the programme and from the successful funding application. Others were elicited and refined in meetings with stakeholders, and with reference to the literature. Data sources for outcome quantification included: the quantitative and qualitative information routinely recorded by the programme management comprising quarterly reports concerning specific activities, training sessions and community events; registers of numbers in attendance and locations and discussions with older people engaging in activities. In addition, the artists were requested to keep reflective diaries on their work, and these were available for analysis. The views of care home personnel were also available through their own reflective diaries. The evaluation team undertook in-depth interviews with activity co-ordinators and care home managers; these informed our choice of proxy costs.

Having identified and categorised our stakeholders, and the outcomes most relevant for each, we went on to apply the following tools of SROI described in the following section: determination of materiality, estimation of proxy costs, consideration of deadweight, displacement, attribution and drop off. We did this through discussion between the evaluation team and the programme implementation team in relation to each of the outcomes considered in the SROI.

\section{Determination of materiality}

In line with guidelines for conducting SROI analysis [21], an outcome was defined as material (i) when it was relevant to and consistent with the scope of the study and (ii) when it was significant in that it could influence decisions and inform good practice. 


\section{Deadweight, displacement, attribution and drop off}

Deadweight responds to the question: 'How much of the outcome would still be attained without the activity delivered?' In order to calculate the percentage of the outcome that would be attained even in the absence of the activity delivered, reference was made to alternative activities available to participating stakeholders. A comprehensive analysis of these was available from a baseline study of the homes, undertaken by Broome et al. [34]. This showed what alternative activities were typically available in the care homes prior to Imagine Arts and who delivered these.

Displacement responds to the question: 'Were there any activities with the same outcome displaced by the intervention being evaluated?' Owing to the scope of the study, teams agreed that little or no displacement of other activities arose from the introduction of arts activities to residential care homes. This is to say that residents were not missing sessions led by the home's activity co-ordinator or an external entertainer when they engaged with the Imagine Arts programme, because the alternative activities were relatively infrequent.

Attribution responds to the question: "Who else contributed to the attainment of the outcome?'

Whereas the literature on SROI contends that the assessment of attribution is imprecise [21] this consideration helped the team to identify all relevant stakeholders and to assess how much of each outcome could be attributed to the delivery of the Imagine programme with due circumspection. An example is the input of care home personnel to the execution of the programme's activities. In practice, in this case, we deemed that the 'cost' to the home was counterbalanced by the 'benefit' to the member of staff who gained ideas and skills from engagement the arts activity. If numerous volunteers were helping with the arts activity, however their input might have raised questions about attribution, but this did not arise.

Drop off responds to the question: "How much of the outcome is lost in the years post intervention?' 
In order to calculate the percentage of the outcome lost in the years after delivery of the intervention, we took into account various factors, including the limited life expectancy of care home residents. Like deadweight, displacement and attribution, drop-off was reduced to a percentage decrease in the value of the outcome. All were applied in the impact table and could be varied in the sensitivity analysis.

\section{Application of monetary value}

The total amount of monetary inputs invested by the funders of the programme (Arts Council England and the Baring Foundation) plus in-kind contributions made by the arts organisations and the City Council were taken into account for the analysis.

In relation to each stakeholder outcome the cost of an alternative activity that would have led to the same outcome, was carefully chosen - a proxy cost. Proxy costs were carefully selected through discussion between the implementation and evaluation teams and with reference to research evidence. The aim was to identify the best available alternative approach to achieving a similar outcome. A good proxy had evidence of effectiveness and sometimes of costs, and at the very least it had to have face validity as an activity that it would be realistic for a care home resident to undertake. We rejected using proxies from the HACT Social Value Bank [35] in favour of a more conservative and concrete approach: only existing services/products with a market price were used as proxies, yielding realistic alternative means to achieve similar outcomes.

All costs were standardised to their value in the year the study commenced (2014-15); some were uprated and some were downrated for this purpose. The present value for each of the forecast years after the completion of the study was calculated by taking into account the discount rate of $3.5 \%$ as suggested in the HM Treasury's Green Book [36]. In addition, we considered the Purchasing Power Parities (PPP) rate as reported by the OECD [37] to calculate the international dollars equivalent of our net present value. 


\section{Report of the impact and calculation of SROI}

The calculation of the SROI took into account the total value of the monetary inputs invested by the funders and the in-kind contributions made by various organisations. In order to calculate the SROI ratio, the deadweight, displacement and attribution were taken into account for each of the outcomes achieved. A percentage of drop off was also estimated for the forecast of one, two, three, and four years after the completion of the study, to assess how much of the outcome would be lost in the years following the intervention. Although some of the outcomes may last for many years, (e.g. confidence, skills), in line with the Vineburgh Regeneration Initiative SROI study [38], we used a 4-year perspective on the impact of the outcomes. We also used a high drop rate that, alongside the consideration of attribution and deadweight, helped to minimise the risk of over-interpretation of the effect of the arts intervention. Specifically, the following calculations have been made:

1) We first calculated the impact for the stakeholder group: we multiplied the cost of the financial proxy by the number of stakeholders experiencing the outcome and subtracted a percentage of deadweight, attribution and displacement. We repeated this for each stakeholder group and added up all the impacts to derive the total impact of the outcomes and subtracted a percentage of drop off for the four years following the intervention.

2) We then applied the discount rate [36] for each of the years following the study ( $r$ in the formula is equal to $3.5 \%$ or 0.035 ) and calculated the Present Value (i.e. Value of the impact for year $1 /(1+r)+$ Value of the impact year $2 /(1+r) 2+$ Value of the impact year $3 /(1+r) 3+$ Value of the impact year $4 /(1+r) 4)$.

3) We subsequently calculated the SROI ratio (i.e. Present value / Value of Inputs).

\section{Results}

\section{Funders}

Arts Council England and the Baring Foundation invested $£ 176,333$ to run the programme during the six quarters from February 2014 until December 2015. This funding covered: all 
arts professionals' inputs, including commissioning costs, evaluation costs and ad hoc expenses such as transport for residents. The in-kind contribution of arts organisations to the project (e.g. outreach programmes and access to their venues) was also estimated to be $£ 45,067$. The in-kind contribution of City Council (e.g. the employment of specialist voluntary staff) was estimated to be $£ 19,167$. Although with planning and designing the intervention the investment was made over 18 months, the arts activities ran for 12 of these months (Box 1 for a structured summary as per CHEERS guidelines).

\section{Beneficiaries}

Over the year, 267 older people participated at least once in the Imagine study. Five outcomes were identified by the stakeholder consultation and documentary review: decreased social isolation, improved mental health, improved mobility, greater community inclusion and improved cognition (Appendix A). In order to accurately estimate the financial value of the proxies used for the achieved outcomes, the time older people spent in the arts activities, as described in the indicator section of the impact map for each of the outcomes, has informed the duration of the proxy activity. In addition, the rates of deadweight and attribution were based on the Craft Café Programme [19].

Older people reported positive feelings towards the arts activities they engaged in:

'I enjoyed it so much, art and movement threaded together so well. Says a lot of the person running it.' She further added: 'It was as enjoyable watching as taking part.'

They also enjoyed coproducing arts for local events:

'What an interest that has just been given to [residential home], with the making of the giant bird to be paraded through the city centre during the ...Carnival - we all enjoyed our small part in the shaping and painting of the feathers - thank you for coming.'

Creating artefact enabled reminiscence among older people who could talk with their peers about experiences they had in the past: 
II wore brown, thick lace gloves on my wedding day. I've always had lace curtains up at my windows too.'

Another resident commented on her previous job occupation:

I worked in a babywear factory right in the city centre. I was a machinist and would make Christening clothes out of lace and they looked lovely.'

In regards to the outcomes, 'decreased social isolation' was operationalised as the number of older people attending more than one workshop and for at least two quarters. The financial proxy used was the unit cost of the attendance to a local authority day care (seven attendances): £59 per client attendance (Unit Costs of Health and Social Care) [39]. Workshops were attended by 181 people for at least two quarters and the monetary equivalent was estimated as $£ 50,256.44$.

'Improved mental health' was operationalised as the number of older people attending more than one activity promoting enjoyment through creative stimulation and for at least two quarters. The financial proxy adopted was six sessions of Singing for the Brain - a widelyused community singing intervention for people with dementia and their carers: $£ 111.24$ per client, based on 6 sessions, £18.54 per session (personal communications with the Alzheimer's Society). A total of 156 individuals achieved this outcome and the financial equivalent estimated was $£ 11,666.71$.

The criterion for 'improved mobility' was attending at least one form of art activity involving physical activity (e.g. engaging with marionettes in a puppetry workshop), of which there were 105 instances The financial proxy identified was the session of physiotherapy, valued at $£ 240.00$ per client (based on a package of 4 sessions) [40]. The impact generated was $£ 16,941.96$.

The outcome 'greater community inclusion' was judged as attending at least one community event, and 74 individuals participated in this way. One of the events attended by the older people was the National Care Home day, for which there was an event involving primary 
school children and their parents, a singer and a pianist from Live Music Now. Another was the city Carnival, in which a small number of beneficiaries processed with the parade in their motorised vehicles suitably adorned. The financial proxy used for community inclusion was the cost associated with one attendance to the local authority day care: $£ 59$ per client (Unit Costs of Health and Social Care) [39]. The impact generated by the outcome was £2,935.26.

The indicator adopted for 'Improved cognition' was attendance on at least one creative workshop (i.e. dancing, singing, and manipulation of puppetry), which 168 people achieved. The financial proxy used was cognitive stimulation therapy: $£ 105.00$ per client (based on a package of 7 sessions, £15 per session, two sessions each week). (Cognitive Stimulation Therapy (CST): Summary of evidence on cost-effectiveness. A paper by Comas-Herrera and Knapp [41]. The impact generated was $£ 11,859.37$.

\section{Activity Co-ordinators}

A total of 8 activity co-ordinators employed in the care homes received training in dementia through Imagine. Two outcomes were identified: Increased skills in caring for older people and increased confidence in using arts interventions in care home settings (Appendix B). The percentages of deadweight and attribution were based on the rates provided by the Cunninghame Housing Association SROI evaluation [42] because this study included project personnel as well as beneficiaries (unlike the Craft café study, which only measured outcomes for direct beneficiaries).

In their reflective diaries, activity coordinators reported:

'I learned about folders for apps to go in and how you can organise the interface to look the same'.

And also 'so good at building people's confidence that they can use technology.'

There was a shared feeling among activity coordinators that the key to delivering an effective art programme is to be interactive with the audience. One activity coordinator reported: 
'We believe that the way the sessions were delivered was in an excellent format, varied and interactive, it is very important not just to talk to the audience but to encourage participation and confidence.'

With respect to the outcomes, 'Increased skills in caring for older people' was operationalised as the number of activity co-ordinators who reported this change in their feedback sheets. The financial proxy used was a two-day training course in creativity and meaningful activities for activity co-ordinators ( $£ 130.00$ per participant) informed by Inspirativearts [43]. Eight activity co-ordinators achieved this outcome and the financial equivalent was estimated as £842.40.

'Increased confidence' was operationalised as the number of activity co-ordinators reporting greater assurance in the use of arts activities in the care home context. The financial proxy used was the small peer-development groups run by a local arts company to build confidence ( $£ 50$ per session for 6 sessions, informed by Inspirativearts [43]. Four activity coordinators achieved this outcome and the impact generated was $£ 972.00$.

Care home personnel

A total of 13 care home personnel received training through Imagine. Two outcomes were identified: Increased skills in caring for older people and increased confidence in using arts interventions with them (Appendix C). The percentages of deadweight and attribution were based on the rates provided by the Cunninghame Housing Association SROI evaluation [42]. Similarly, to what was reported by activity coordinators, care home personnel thought: 'The sessions illustrated that you can do adventurous art workshops (with quite simple ideas and materials) with really good results - quite easily.'

Care home personnel felt that the training received proved beneficial for their decision making when working with older people: 
Increased confidence because of the information provided - which will inform my decision making. A great deal of practical information which will help with activity planning. Its opened lots of doors for further research and investigation.'

With respect to the outcomes attained, 'Increased skills in caring for older people' was operationalised as the number of care home personnel attending training courses and reporting increased skills in working with older people. The financial proxy used was the Creative Expressive Therapies course designed to develop communications skills and coping strategies (1 day course): $£ 120.00$ per person (inspirativearts.co.uk) [43]. Five care home personnel achieved this outcome and the financial equivalent estimated was $£ 486.00$.

'Increased confidence in using arts intervention for older people' was operationalised as the number of care home personnel attending arts activities alongside older people. The financial proxy used here was also the Creative Expressive Therapies course cited above [43]. Eight care home personnel achieved this outcome and the monetary equivalent was estimated as $£ 777.60$.

\section{Implementers}

A total of 27 Artists participated in the Imagine study and received training in dementia. Two outcomes were identified for artists and confirmed by reading their reflective diaries: Improved knowledge about dementia and improved confidence on how to support older people. A third, unanticipated outcome was also identified: decreased sense of control in the delivery of the activity (Appendix D). Following discussion with artists, it was evident that their participation in the Imagine study was the only opportunity for them to perform artistically and engage with older people with and without dementia. For this reason, the evaluation and implementation teams agreed that a lower percentage of deadweight and attribution (equal to $10 \%$ each) was an adequate estimate.

Artists agreed on the fact that the delivery of arts activities in care homes may prove an effective way to learn how to: 
'Adapt to different needs of each individual I worked with. Patience - slowing down and simplifying while still taking risks. Finely tuning my observations and responses to each individual I worked with.'

One artist reported on her experience of using imagery as part of her artistic production:

'The warm up where I was using imagery for flicking paint... got nearly everyone joining in. Lots of big arm movements; people unfolding their arms to take part. Eye contact between the participants and lots of laughter. Residents appear to really like discussing the art and sharing their opinions.'

In regards to the outcomes, 'Improved knowledge about dementia' was operationalised as the number of artists reporting this in their interviews or diaries. The financial proxy used was the cost of attendance on a one-day course in Understanding Dementia: $£ 145.00$ (Alzheimers.org.uk) [27]. Five artists achieved this outcome and the financial equivalent was estimated as $£ 587.25$.

'Improved confidence on how to support older people' was operationalised as the number of artists reporting an improved knowledge on how to implement art programmes for older people. The financial proxy used was the cost of a one-day course in how to build confidence to support older people living with dementia: $£ 160.00$ per person (Alzheimers.org.uk) [44]. Sixteen artists reported improved confidence and the monetary equivalent estimated was $£ 2,073.60$.

'Decreased sense of control in the delivery of the activity' was thrown up by some of the diaries and from observations in the field. Artists mentioned that they were not comfortable working with such large groups, while care homes expected them to occupy all the residents in a given lounge. This negative outcome was therefore operationalised as the number of artists reporting a decreased confidence in the use of arts activities for older people as a result of unexpected occurrences during the delivery of the art programme. The negative 
financial proxy used was the one-day training course cited above [44]. Six artists reported feeling a lack of control and the negative impact was minus $£ 777.60$.

\section{$\underline{\text { Promoters }}$}

\section{Care home providers}

A total of five care home providers took part in the Imagine study. The relevant outcome identified was enhanced reputation through association with the programme (Appendix E). We used the deadweight and attribution rates as provided by the Craft Café Programme SROI evaluation [19].

The Imagine programme was very well received by care home managers who felt included in the delivery of the creative programme and this increased the variety of activities that the care home may offer to the residents:

'Technology and Dementia are two areas that don't usually go hand in hand, but we were able to get the full benefit of top expertise. The Imagine programme put together a programme for utilising the ipad within a care home setting to make a range of creative activities available. Specialist artists also helped to show us how these could be used with various scenarios and they will be working with us and our residents.'

‘Enhanced reputation' was operationalised as the number of care home providers referring to the programme in their web platforms or marketing material. The financial proxy adopted was estimated through consultation with care home managers involved in the study and it was an estimated cost of a marketing contract: $£ 3,000.00$. Five care home providers achieved this outcome and the monetary equivalent was estimated as $£ 11,092.50$.

\section{Estimating the SROI ratio}

It has been recommended that a robust approach to SROI is to include the outcomes only for intended beneficiaries. If we include only the outcomes for the beneficiaries (care home residents activity-coordinators and care home personnel) the SROI yields a ratio of $£ 1.07$ of 
social value for each $£ 1.00$ invested (refer to Data in Brief). Over 4 years, adjusted for inflation, this corresponds to a present value of $£ 93,466.41, £ 79,078.58, £ 49,843.87$, $£ 36,404.98$ respectively. This amounts to a total present value of $£ 258,793.84$ and a net present value of $£ 18,227.19$. This net present value represents the profitability of undertaking arts interventions for older people living in care homes minus the initial monetary input invested.

If we include the outcomes for all stakeholders included in the impact map, (care home residents, activity-coordinators, care home personnel, artists and care home providers) this SROI analysis yields a ratio of $1.20: 1$, indicating $£ 1.20$ of social value every $£ 1.00$ invested. The forecast indicated a present value of each year of $£ 106,003.37, £ 79,078.58$, $£ 59,284.51, £ 44,651.98$ respectively. This comes to a total present value of $£ 289,018.44$ and a net present value of $£ 48,451.79$. This is equivalent to a present value of $\$ 26,416.21$. When we include all the outcomes of all the stakeholders benefiting from the Imagine programme, The PPP conversion yields a net present value of $\$ 70,219.98$.

We ran sensitivity analysis to calculate how much change is needed to make the SROI ratio equal to $£ 1$ every $£ 1$ invested [21]. The sensitivity analysis indicates that, when values considered in the SROI analysis are further decreased, the SROI ratio does not fall below 1.02:1.00. Therefore, even if the worst-case assumptions held true, thus if we consider a displacement rate of $15 \%$ for all the outcomes of all participating stakeholders, the Imagine study is unlikely to report a ratio that is less than $£ 1.02$ for every $£ 1.00$ invested (Table 2).

\section{Discussion}

As shown in the impact map (Table 1), 181 out of 267 older people living in care homes who participated in the Imagine programme are likely to have benefitted through reduced social isolation. Mental health is likely to have improved for 158 residents and cognition for 168 . In line with findings from a recent review on the effectiveness of participatory arts activities for older people, whereby the authors found a positive association across studies between the 
engagement of older people in different dance performances and muscle endurance, improved agility and balance, and better social inclusion [45], 105 of our participants are likely to have improved their mobility. We estimate that 74 increased their community inclusion through participating in the programme. Smaller numbers of care home personnel, activity co-ordinators and artists achieved professional outcomes of importance to the quality of residential care. A clearly-positive ratio emerges in favour of the Imagine programme, whether the core group of beneficiaries alone is included or not. This indicates that the delivery of arts interventions in care homes is a justifiable use of resources because it generates additional public value. Our best estimate is that the programme returned at least 1.2 times the investment, which improvements in physical and psychological health, cognitive functioning and social inclusion for care home residents. This is consistent with the findings of Coulton, Clift, Skingley, and Rodriguez [13] in a community setting. More broadly, the benefits can be shown to include greater skills and confidence in the personnel who work in care homes, as well as improved confidence (on balance) on the part of arts practitioners in working with older people and those with dementia. This is consistent with the results of the Bealtaine evaluation by O'Shea and Leime [46]. However, as the SROI methodology is highly sensitive to the context in which takes place, the findings have limited generalisability [15].

The study is characterised by several limitations. We lack independent verification of clinical changes such as cognition or mobility. The observational design of this study, lacking a control group, makes it impossible to draw firm conclusions. It would be mistaken to generalise to other arts interventions in other contexts.

The present study did not take into account the magnitude of the benefits of arts interventions on individual stakeholders. Positive outcomes achieved may be the result of the interplay of several variables associated with the experience, which were not observed in this study. 
Only a small number of participants attended the activities consistently. This may be due to their general infirmity or an indication of their personal preferences - older people were consulted with as part of the programme development but we do not know whether their preference with respect to the activity to attend changed over time as this was not recorded regularly. Also, we do not know if they were indisposed or opting out of regular attendance, as only numbers in attendance, not names, were recorded. It follows that the impact of some of the activities delivered may have decreased over time. The employment of a before/after research design alongside a consistent monitoring of attendances and recording of participants' preferences may help increase the strength of the study.

Furthermore, the individuals who participated are likely to be highly self-selected. While a wide range of activities was made available through the programme, we cannot say how far it penetrated the care home population as a whole. Future studies may wish to explore what activities appeal to which residents and why.

Where costs are fixed, as in providing an intervention in a care home, the attendance of a greater number of participants naturally brings down the unit cost per person. Therefore, if larger numbers had attended the events, this would have led to a higher return on investment as well as overall greater benefits to the participating audiences. At the same time, interventions in care homes need to be flexible to adapt to the characteristics of the residents, whose needs and abilities may make it difficult to include larger numbers in specific sessions.

Our study did not have a control group to check for the attribution rate, this may have reduced our ability to clearly establish how much of the outcome was due to our arts interventions. However, we referenced our rate with reference to the literature employing similar estimates for the evaluation of SROI for arts interventions in housing associations.

Several strengths are associated with the study. The programme was facilitated by the active participation of older people during the whole period of the study. Older people were 
acting as co-commissioners, study participants and audience to workshops and community events. The evidence examined here of positive outcomes for beneficiaries, promoters and implementers has substantial implications for funders, commissioners and providers of care as well as practising artists. Funders of the arts in care homes should regard investment in this area as worthy of further experimentation and evaluation. The provision of arts activities may be a source of publicity for the sustainment of care homes to attract new residents, especially for those that are privately-funded.

Public sector commissioners of services need to explore how the magnitude and persistence of benefits demonstrated here compare to alternative interventions, such as those which are used as proxies. This can be judged using the SROI approach or more conventional costeffectiveness analysis. Providers of care should note the benefits which staff report from the arts interventions. Artists working in this field should draw confidence from these results which demonstrate the potential effectiveness of their input.

\section{Conclusions}

Economic constraints and the search for value for money from public expenditure make it desirable to identify which investments yield the greatest benefits for participating stakeholders. This has shifted the focus from a consideration of outcomes based on an economic perspective of cost effectiveness where outcomes are narrowly defined to a more holistic approach with regard to the individual, and a more inclusive approach with regard to the social context.

This study used an SROI methodology to evaluate the social value generated through the attendance of stakeholders to the activities delivered as part of the Imagine study.

Through a reflective and transparent SROI analysis we hope to have successfully:

- Identified the stakeholders and beneficiaries of a complex programme.

- Elucidated the relevant outcomes in this context.

- Estimated the value of individual activities in relation to realistic alternatives. 
- Indicated the most cost-efficient arts activities in the Imagine programme.

- Highlighted areas for improvement in future evaluations.

From our findings it appears that in order to deliver an effective art programme in residential homes for older people, where a proportion of residents are bound to have dementia, care home personnel and artists need to work together closely in a spirit of knowledge exchange. For example, in our study we found an unintended outcome of decreased sense of control among artists. This issue could be addressed through providing adequate dementia awareness to artists prior to their involvement in arts intervention delivery, so that they understand that ceding control to a certain degree may be desirable when co-producing arts interventions with people with dementia.

\section{Ethical approval:}

This SROI analysis is based on routinely collected monitoring information and no direct contact with patients took place, for this reason no ethical approval was needed. However, ethical approval was attained for the Imagine study which is the study this SROI is based on.

\section{Ethics, consent and permission/consent to publish:}

No recruitment nor direct contact with participants took place for this SROI study. However, participants recruited as part of the Imagine study gave their written consent to participate in the study and their consent to publish.

\section{List of abbreviations}

SROI: Social Return on Investment

Competing interests: None declared 


\section{References}

[1] J. Taylor, J., C. Bradbury-Jones, International principles of social impact assessment: lessons for research? Journal of Research in Nursing, 16(2) (2011) 133-145.

[2] A. O. Banke-Thomas, B. Madaj, A. Charles, N. van den Broek, Social Return on Investment (SROI) methodology to account for value for money of public health interventions: a systematic review, BMC Public Health, 15(1) (2015) 582.

[3] M. Cook, The Public Services (Social Value) Act. http://www.socialenterprise.org.uk/uploads/files/2012/03/public services act 2012 a brief guide web version final.pdf, 2012 (accessed 30 June 2016).

[4] Care Quality Commission (CQC), Care Quality Commission to provide residential and nursing care. http://www.cqc.org.uk/location/1-332561547/reports, 2015 (accessed 30 June 2016).

[5] E. Broome, T. Dening, J. Schneider, Facilitating Imagine Arts in residential care homes: the artists' perspectives, Arts \& Health, (2017) 1-13.

[6] J. Wenborn, D. Challis, J. Head, C. Miranda-Castillo, C. Popham, R. Thakur, ... M. Orrell, Providing activity for people with dementia in care homes: a cluster randomised controlled trial, International Journal of Geriatric Psychiatry, 28(12) (2013) 1296-1304.

[7] B.J. Fisher, D.K. Specht, Successful aging and creativity in later life. Journal of aging studies, 13(4) (1999) 457-472.

[8] M. Woollacott, A. Shumway-Cook, Attention and the control of posture and gait: a review of an emerging area of research, Gait \& posture, 16(1) (2002) 1-14.

[9] R. Young, P.M. Camic, V. Tischler, The impact of community-based arts and health interventions on cognition in people with dementia: A systematic literature review, Aging \& mental health, 20(4) (2016) 337-351.

[10] P.M. Camic, C.M. Williams, F. Meeten, Does a 'Singing Together Group' improve the quality of life of people with a dementia and their carers? A pilot evaluation study, Dementia, 12(2) (2013) 157-176.

[11] S. MacPherson, M. Bird, K. Anderson, T. Davis, A. Blair, An art gallery access programme for people with dementia: 'You do it for the moment', Aging \& Mental Health, 13(5) (2009) 744-752.

[12] A. Skingley, S. De'Ath, L. Napleton, Evaluation of edna: arts and dance for older people, Working with Older People, 20(1) (2016) 46-56.

[13] S. Coulton, S. Clift, A. Skingley, J. Rodriguez, Effectiveness and cost-effectiveness of community singing on mental health-related quality of life of older people: randomised controlled trial, The British Journal of Psychiatry, 207(3) (2015) 250-255.

[14] L.J. Phillips, S.A. Reid-Arndt, Y. Pak, Effects of a creative expression intervention on emotions, communication, and quality of life in persons with dementia, Nursing research, 59(6) (2010) 417. 
[15] G.D. Cohen, The creativity and aging study: The impact of professionally conducted cultural programmes on older adults, (2006).

[16] L. Archer, S. Davidson, J. Iparraguirre, M. Kohler, B. Pursch, J. Vass, F. Curran, Creative and Cultural Activities and Wellbeing in Later Life, Age UK, London, 2018.

[17] E. Broome, T. Dening, J. Schneider, D. Brooker, Care staff and the creative arts: exploring the context of involving care personnel in arts interventions, International Psychogeriatrics, 29(12) (2017) 1979-1991. doi: 10.1017/s1041610217001478

[18] Department for Business Innovation and Skills, Learning for older people in care settings: A guide for activity coordinators and care staff.

http://shop.niace.org.uk/media/catalog/product/c/o/coordinators and care staff-final.pdf, 2014 (accessed 13 April 2016).

[19] Social Value Lab, Craft Cafe. Creative Solutions to Isolation and Loneliness, Social Return on Investment Evaluation, Report for Impact Arts, Social Value Lab, Glasgow, 2011.

[20] J. Emerson, M. Cabaj, Social Return on Investment, Making Waves, 11, (2000) 10-4.

[21] The SROI Network. http://www.thesroinetwork.org/publications/doc details/241-a-guideto-social-return-on-investment-2012, 2011 (accessed 06 April 2016).

[22] R. Millar, K. Rall, Social return on investment (SROI) and performance measurement: The opportunities and barriers for social enterprises in health and social care, Public Management Review, 15(6) (2013) 923-941.

[23] M. Arvidson, F. Lyon, S. McKay, D. Moro, Valuing the social? The nature and controversies of measuring social return on investment (SROI), Voluntary Sector Review, 4(1) (2013) 3-18.

[24] G. Krlev, E. Bund, G. Mildenberger, Measuring what matters-Indicators of social innovativeness on the national level, Information Systems Management, 31(3) (2014) 200224.

[25] L. Mook, J. Maiorano, S. Ryan, A. Armstrong, J. Quarter, Turning Social Return on Investment on its head: The Stakeholder Impact Statement, Nonprofit Management \& Leadership, 26 (2) (2015) 229-246.

[26] G. Whelan, Understanding the social value and well-being benefits created by museums: A case for social return on investment methodology, Arts \& Health, 7(3) (2015) 216-230.

[27] A. O. Banke-Thomas, B. Madaj, A. Charles, van den Broek, Social Return on Investment (SROI) methodology to account for value for money of public health interventions: a systematic review. BMC Public Health, 15 (2014) 582. DOI:

10.1186/s12889-015-1935-7

[28] BrandonCare, Social Return on Investment Pilot Report. https://www.brendoncare.org.uk/images/uploads/downloads/September-SROI-report.pdf, 2011 (accessed 2 May 2016). 
[29] All-Party Parliamentary Group on Arts Health and Wellbeing, Creative Health: The Arts for Health and Wellbeing, second ed., Inquiry Report, 2017.

[30] Office of National Statistics: Census. https://nottinghaminsight.org.uk/insight/keydatasets/census-2011.aspx, 2011 (accessed 30 June 2016).

[31] Husereau D, Drummond M, Petrou S, Carswell C, Moher D, Greenberg D, Augustovski $\mathrm{F}$, Briggs $\mathrm{AH}$, Mauskopf J, Loder E. Consolidated health economic evaluation reporting standards (CHEERS) statement. Cost Effectiveness and Resource Allocation. 2013 Dec;11(1):6.

[32] J.E. Nicholls, E. Lawlor, Neitzert, T. Goodspeed, A Guide to Social Return on Investment. SROI Network, Liverpool, UK, 2012. Available at: http://www.socialvalueuk.org/app/uploads/2016/03/The\%20Guide\%20to\%20Social\%20Retur n\%20on\%20Investment\%202015.pdf

[33] The Museum of Modern Art, The MoMA Alzheimer's Project: Making Art Accessible to People with Dementia. https://www.moma.org/visit/accessibility/meetme/

[34] E. Broome, B. Jones, T. Dening, J. Schneider, V. Tischler, Bringing arts interventions into care settings. Journal of Dementia Care, 25(6) (2017) 24-26.

[35] HACT Social Value Bank. http://www.hact.org.uk/social-value-bank. (accessed 25 June 2016).

[36] HM Treasury, The Green Book: Appraisal and Evaluation in Central Government, London, 2011.

http://www.gov.uk/government/uploads/system/uploads/attachment_data/file/220541/green_ book_complete.pdf. (accessed 01 July 2016).

[37] OECD Publishing, OECD Digital Economy Outlook, OECD Publishing, 2017.

[38] Vineburgh Regeneration Initiative SROI study.

http://www.socialvalueuk.org/app/uploads/2016/03/Vineburgh\%20SROI\%20Report\%20Final $\% 20$ Assured.pdf. (accessed 8 July 2016).

[39] L. Curtis, A. Burns, Unit Costs of Health and Social Care.

http://www.pssru.ac.uk/project-pages/unit-costs/2015/, 2015 (accessed 8 July 2016).

[40] Nuffield-Health. https://www.nuffieldhealth.com/physiotherapy/faqs, 2016 (accessed 28 June 2016).

[41] A. Comas-Herrera, M. Knapp, Cognitive Stimulation Therapy (CST): summary of evidence on cost-effectiveness, 2016.

[42] The Cunninghame Housing Association SROI. http://www.socialvalueuk.org/app/uploads/2016/03/Vineburgh\%20SROI\%20Report\%20Final \%20Assured.pdf, 2014 (accessed 15 April 2016).

[43] Inspirativearts. http://www.inspirativearts.co.uk/. (accessed 25 June 2016). 
[44] Alzheimer's Society.

https://www.alzheimers.org.uk/site/scripts/documents_info.php?documentID=2883.

(accessed 30 June 2016).

[45] J.W. Keogh, A. Kilding, P. Pidgeon, L. Ashley, D. Gillis, Physical benefits of dancing for healthy older adults: a review, Journal of aging and physical activity, 17(4) (2009) 479-500.

[46] E.A.M.O.N. O'Shea, A.N. Léime, The impact of the Bealtaine arts programme on the quality of life, wellbeing and social interaction of older people in Ireland, Ageing \& Society, 32(5) (2012) 851-872. 


\section{Box 1. Structured summary as per CHEERS guidelines.}

Background Direct involvement in creative activities can have benefits in terms of improved attention and positive engagement for older people. However, the literature is still scant on the social and economic values of these activities.

Objective We used the Social Return on Investment approach (SROI) to explore the social and economic benefits of arts activities for older people living in residential homes in England.

Design Economic evaluation by means of SROI approach to assess the social value of arts intervention for people with and without dementia living in care homes. We complied with the CHEERS checklist and followed the six stages of SROI as reported in the literature.

Data Sources Quantitative and qualitative information routinely recorded by the programme management comprising quarterly reports concerning specific activities, training sessions and community events; registers of numbers in attendance and locations and discussions with older people engaging in activities. In addition, the artists were requested to keep reflective diaries on their work, and these were available for analysis. The views of care home personnel were also available through their own reflective diaries. The evaluation team undertook in-depth interviews with activity co-ordinators and care home managers; these informed our choice of proxy costs.

Target Population Older residents with and without dementia.

Time Horizon Costs were evaluated over four years after the intervention.

Perspective The direct perspective of participants. Participants were consulted throughout data gathering.

Intervention the arts activities ran for 12 months and 267 older people participated at least once in the Imagine study. The arts intervention was Professionally-led by artists and delivered in care homes for residents with and without dementia.

Outcome Measure The outcome measures were reported for all stakeholders as this helped triangulate the findings and assess the social value of the arts intervention. Stakeholders were: people with dementia, care home personnel and activity co-ordinators. For people with and without dementia the outcome measures were: Level of community inclusion, mental and physical health, improved cognition and decreased social isolation. For care home personnel and activity co-ordinators the outcomes were: improved skills in caring for older people and increased confidence in using arts intervention. For artists the outcome measures were: improved knowledge on dementia and improved confidence in using arts for older people. For care home providers the outcome measure was enhanced reputation through association with the arts programmes.

Results of Base-case Analysis The analysis yielded an SROI of $£ 1.20$ for every $£ 1$ of expenditure. The forecast for the four years following the intervention indicated a present value of $£ 106,003.37, £ 79,078.58$, $£ 59,284.51, £ 44,651.98$ for each year respectively. Total present value of $£ 289,018.44$ and a net present value of $£ 48,451.79$. The PPP conversion rate yields a net present value of $\$ 70,219.98$.

Results of Sensitivity Analysis Even if the worst-case assumptions held true, thus if we consider a displacement rate of $15 \%$ for all the outcomes of all participating stakeholders, the Imagine study is unlikely to report a ratio that is less than $£ 1.02$ for every $£ 1.00$ invested.

Limitations Lack of a control group to check for the attribution rate, this may have reduced our ability to clearly establish how much of the outcome was due to our arts interventions.

Conclusions. Funders of arts activities in care homes should regard investment in this area as worthy of further experimentation and evaluation.

Primary Funding Source Arts Council England and the Baring Foundation (investment of $£ 176,333$ to run the programme from February 2014 until December 2015). This funding covered: all arts professionals' inputs, including commissioning costs, evaluation costs and ad hoc expenses such as transport for residents. 
Table 1. Preferences towards art activities.

\begin{tabular}{|l|l|}
\hline Artforms & Nominations \\
\hline Armchair art gallery & 27 \\
\hline Dance & 57 \\
\hline Digital arts & 18 \\
\hline Drama & 29 \\
\hline Making costumes & 22 \\
\hline Music & 89 \\
\hline Performances broadcast live & 43 \\
\hline Puppetry & 30 \\
\hline Singing/choirs & 86 \\
\hline Visiting art galleries & 52 \\
\hline Visual arts & 71 \\
\hline Creative writing & 9 \\
\hline
\end{tabular}


Table 2. Sensitivity analysis.

\begin{tabular}{|c|c|c|c|}
\hline Item & Base case & New case (Assumption) & SROI \\
\hline Deadweight & $10-25 \%$ & $25 \%$ Deadweight for all outcomes & $1.07: 1$ \\
\hline Displacement & $0 \%$ & 15\% Displacement for all outcomes & 1.02:1 \\
\hline Attribution & $10-19 \%$ & $25 \%$ Attribution for all outcomes & 1.09:1 \\
\hline Drop-Off & $10-25 \%$ & $25 \%$ Drop Off for all outcomes & $1.15: 1$ \\
\hline $\begin{array}{l}\text { Overlap of } \\
\text { Deadweight, } \\
\text { Displacement, } \\
\text { and attribution }\end{array}$ & Impact map & $\begin{array}{l}20 \% \text { all rates for all outcomes of older people } \\
15 \% \text { all rates for all outcomes for the other stakeholders } \\
\text { Drop off at } 15 \% \text { for all outcomes of older people } \\
\text { Drop off at } 10 \% \text { for all outcomes for the other stakeholders }\end{array}$ & $1.04: 1$ \\
\hline \multirow[t]{5}{*}{$\begin{array}{l}\text { Proxies older } \\
\text { people* }\end{array}$} & \multirow[t]{5}{*}{ Impact Map } & $\begin{array}{l}\text { - Outcome 1: Social isolation } \\
7 \text { sessions of Day care ( } £ 45 \text { per client, session lasting } \\
\text { only } 3.5 \text { hours). } \\
\text { [Unit Costs of Health and Social Care 2015] }\end{array}$ & \multirow{5}{*}{ 1.08:1 } \\
\hline & & $\begin{array}{l}\text { - Outcome 2: Mental Health } \\
6 \text { sessions of Behavioural activation delivered by a } \\
\text { non-specialist ( } £ 15.00 \text { per client session) } \\
\text { [Unit Costs of Health and Social Care 2015] }\end{array}$ & \\
\hline & & $\begin{array}{l}\text { - } \quad \text { Outcome 3: Physical health } \\
4 \text { sessions of physiotherapy ( } £ 34.00 \text { per session) } \\
\text { [Unit Costs of Health and Social Care 2015] }\end{array}$ & \\
\hline & & $\begin{array}{l}\text { - Outcome 4: Community inclusion } \\
1 \text { of Day care ( } £ 45 \text { per client, session lasting only } 3.5 \\
\text { hours). } \\
\text { [Unit Costs of Health and Social Care 2015] }\end{array}$ & \\
\hline & & $\begin{array}{l}\text { - } \text { Outcome 5: Cognition } \\
\text { One membership to YMCA for older people plus one } \\
\text { Pay-as-you-go session price (£44.70 per client, for } \\
\text { membership and seven classes). } \\
\text { [http://www.ymcaclub.co.uk/join/personal- } \\
\text { memberships]. }\end{array}$ & \\
\hline $\begin{array}{l}\text { Outcome Older } \\
\text { people }\end{array}$ & Impact Map & Only $85 \%$ of outcomes achieved & 1.05:1 \\
\hline $\begin{array}{l}\text { Outcome } \\
\text { Artists }\end{array}$ & Impact Map & Only $50 \%$ of outcomes achieved & $1.18: 1$ \\
\hline $\begin{array}{l}\text { Outcome Care } \\
\text { home } \\
\text { providers }\end{array}$ & Impact Map & Only $50 \%$ of outcomes achieved & $1.11: 1$ \\
\hline $\begin{array}{l}\text { Outcome } \\
\text { Activity Co- } \\
\text { ordinators }\end{array}$ & Impact Map & Only $50 \%$ of outcomes achieved & $1.18: 1$ \\
\hline $\begin{array}{l}\text { Outcome Care } \\
\text { home } \\
\text { personnel }\end{array}$ & Impact Map & Only $50 \%$ of outcomes achieved & 1.19:1 \\
\hline $\begin{array}{l}\text { All outcomes } \\
\text { of stakeholders }\end{array}$ & Impact Map & Only $90 \%$ of outcomes achieved & $1.06: 1$ \\
\hline
\end{tabular}

*Attribution at 10\%; Deadweight 5\% 